NORDISK MUSEOLOGI $1996 \cdot 2$, S. 57-70

\title{
EN BIBLIOGRAFI OM ØKOMUSEER
}

\author{
John Aage Gjestrum
}

Hugues de Varine, som var den som «oppfant» ordet økomuseum, har beskrevet bvordan dette skjedde (de Varine 1978). Mot slutten av 1960-tallet var det tydelig for stadig flere at det tradisjonelle museet var kommet i ei krise. Det representerte eksklusive deler av befolkningen og syntes å ha mistet betydning som element for samfunnsutviklingen. Samtidig ble de utfordringer menneskeheten stod overfor tydeligere og tydeligere, - både på det sosiale plan med fattigdomsproblemene i store deler av verden og på det økologiske plan, der det nettopp på denne tida ble tydelig at det moderne samfunn var i ferd med å passere naturens tålegrenser.

Den internasjonale museumsorganisasjonen ICOM har fra etableringen i 1946 spilt en hovedrolle i å skape kontakter mellom museumsfagfolk og få til utveksling av idéer over landegrensene. Det var derfor ganske naturlig at deler av den kritiske diskusjonen omkring museenes vanskelige situasjon kom til å skje i fora knyttet til ICOM. Som direktør i ICOM havnet derfor Hugues de Varine også midt oppi problemene. Han kom til à spille en viktig rolle som kontaktskaper mellom ulike initiativer der nye ideer for museet ble utprøvd, og han satt i en posisjon med stor innflytelse. Han har fortalt hvordan selve ordet økomuseum ble til nærmest ved en tilfeldighet:

I 1971 under ICOMs generalkonferanse som fant sted i Grenoble i Frankrike, skulle den franske miljøministeren M. Robert Poujade holde en tale til deltakerne. Ministeren som gjerne skulle ta opp spørsmål om miljø, natur, økologi, kultur og samfunnsdebatt, nølte med å bruke ordet museum i denne sammenhengen. Under et måltid som fant sted i Paris, forsøkte Georges Henri Rivière, tidligere direktør i ICOM, og jeg, som da var direktør i ICOM, å overtale miljøministerens nærmeste medarbeider og få ham til å forstå at museet var en levedyktig institusjon som hadde en viktig rolle å spille når det gjelder å bevisstgjøre hele samfunnet om vår kultur og forholdet til naturen.

Under samtalen forsøkte jeg som en slags spøk å finne på et nytt ord ettersom det gamle, museet, var så vanskelig å akseptere og bruke i en ny sammenheng. Etter flere forsøk kastet jeg fram ordet økomuseum. Mitt forslag ble godt mottatt, og noen dager etterpå ble det miljøministeren som for første gang brukte ordet offisielt. Foran museumsfolk fra hele verden, som deltok på ICOMs generalforsamling, sa han: «Nå er vi på veg mot noe nytt, noe som enkelte allerede kaller økomuseer.» 
John Aage GJESTRUM

Denne erklæringen åpnet nye og store perspektiver for opprettelsen av en ny museumstype som skulle ta hele det menneskelige miljø i betraktning, og som skulle hjelpe lokalsamfunnet til å forstå og forsvare dette miljøet. Økomuseet var født. (de Varine 1978, i norsk versjon Gjestrum/Maure 1988: 105).

Mens Hugues de Varine formet ordet økomuseum, var det hans forgjenger som ICOM-direktør, nå på 1970-tallet ICOMs permanente rådgiver, Georges Henri Rivière, som i stor grad formulerte hva som skulle legges i dette nye museumsbegrepet (Rivière 1985). I Frankrike kom de første tre økomuseene i 1972 - ministeren som hadde brukt ordet økomuseum først måtte jo følge opp (!). To av dem var museer opprettet i 1967 knyttet til regionale parker: Musée de la Grande Lande à Marquèze (Parc Régional des Landes de Gascogne), og Ile d'Ouessant (Parc Régional d'Armorique). Dette var lokale museumsprosjekter i tråd med idéer Rivière hadde arbeidet med gjennom mange tiår, og som nå fikk sin profilering knyttet til økomuseumsbegrepet. Det tredje økomuseet i 1972 var l'Ecomusée du la Communauté Le CreusotMontceau-Les-Mines. I motsetning til det vi kan kalle park-økomuseene lå dette i et industrisamfunn. Museets eksperimentelle karakter som redskap for lokalsamfunnsutvikling markerer et mer radikalt syn på økomuseets sosiale rolle.

Disse to typene preget utviklingen av de franske økomuseene, som etter ti års tid tellet omkr. 30 museer. Rivière fortsatte å spille en aktiv rolle, og formulerte sin definisjon av økomuseet, - en definisjon som gjennomgikk stadig nye endringer fram til 1980, og som Rivière hele tida kalte en «Définition évolutive»:
An ecomuseum is an instrument conceived, fashioned and operated jointly by a public authority, and a local population [...].

It is a mirror in which the local population views itself to discover its own image, in which it seeks an explanation of the territory to which it is attached and of the populations that have preceded it [...] It is a mirror that the local population holds up to visitors [...].

It is an expression of man and nature. It situates man in his natural environment. It portrays nature in its wildness, but also as adapted by traditional and industrial society in their own image.

It is an expression of time, when the explanations it offers reach back before the appearance of man, ascend the course of the prehistoric and historical times in which he lived and arrive finally at man's present. It also offers vistas of the future, while having no pretentions to decision-making, its function being rather to inform and critically analyse [...].

It is an interpretation of space [...].

It is a laboratory [...].

It is a conservation centre [...].

It is a school, in so far as it involves the population in its work of study and protection and encourages it to have a clearer grasp of its own future. [...] (Utdrag fra Rivière 1985).

Den nære forbindelsen mellom økomuseene som nye museumseksperimenter og ICOMs toppledelse gjorde at prosjektene raskt fikk stor internasjonal oppmerksomhet. Det skjedde gjennom publisering i ICOMs fora, og ved at museumfolk fra hele verden oppsøkte de franske økomuseene og tok idéene med hjem og tilpasset de til andre kontekster. Med et 25-års perspektiv kan det i ettertid ikke være tvil om at økomuseumsidéene har representert noe av det viktigste som har skjedd i fornyelsen av museumsinstitusjonene. Og da ikke bare knyttet til gjennomføringen av de 
ulike økomuseumsprosjekter, men også fordi det er blitt skapt miljøer i mange land for en kritisk omvurdering av de tradisjonelle museene.

\section{LITTERATUREN OM ØKOMUSEENE}

Den som skal nærme seg økomuseumsfenomenet gjennom litteraturen, vil møte det umiddelbare problem at det er skrevet nokså mye om økomuseer innen enkelte land, men lite ut fra et mer overblikkende perspektiv. Det er gjort flere avhandlingsarbeider om økomuseer, men de er stort sett ikke utgitt og er derfor vanskelige å få tak i.

Et godt startsted kan være temanummeret Images of the ecomuseum av MUSEUM, ICOMs og UNESCOs museumstidsskrift, som utkom i 1985 (nr. 148, 1985/4). Her gjengis Rivières tredje og siste versjon av hans definisjon av økomuseet (også oversatt til svensk i Svenska Museer 1986/4-5: 32), og gode oversiktsartikler ved Hugues de Varine, François Hubert, Jean-Yves Veillard, Mathilde Scalbert, Max Querrien og Pierre Mayrand. Eksempelprosjekter fra de ulike land presenteres ved René Rivard (Québec), Kjell Engström (Sverige), António Nabais (Portugal), John R. Kinard (USA), Milagro Gomez de Blavia (Venezuela), Alpha Oumar Konaré (Mali), Fernanda de Camargo e Almeida-Moro (Brazil) og Alfredo Crus-Ramirez (Tyskland).

En absolutt klassiker i økomuseumssammenheng er de Varines artikkel $A$ fragmented museum - om Le Creusot i MUSEUM fra 1973 (oversatt til dansk 1976, til norsk 1988). Her introduserer de Varine idéen om at alle gjenstander $\mathrm{i}$ et distrikt psyko- logisk sett er en del av økomuseet, en type "kulturell» eiendomsrett, som ikke har noe med juridisk eiendomsrett å gjøre. Alle objekt i regionen kan derfor være disponible for museet (de Varine 1973). En viktig innføringsartikkel er også de Varines tekst Om okomuseet i Gazette (1978, norsk oversettelse 1988).

En annen fin innføring er René Rivards Opening up the museum - or Towards a new museology: ecomuseums and "open" museums som han skrev etter å ha studert et halvt hundre økomuseer og museer i Amerika og Europa på oppdrag fra canadiske museer. Manuskriptet ble offentliggjort i 100 eksemplarer i tilknytning til det første internasjonale arbeidsseminar for økomuseer og ny museologi i Québec 1984. Det skulle utgis i bokform året etter, noe som imidlertid ikke skjedde. Manuskriptutkastet har derfor sirkulert som «underground-stensil» i økomuseumsmiljøene. Det finnes i både fransk og engelsk språkversjon, men kan være vanskelig tilgjengelig ettersom det aldri ble offisiellt utgitt.

Innenfor det nordiske språkområdet er det grunn til å peke på to oversiktspublikasjoner: Økomuseumsboka - som ICOMs nasjonalkomité i Norge ga ut, egentlig som en oppfølging av et større seminar i 1984 som introduserte økomuseumsidéene i Norge (Gjestrum/Maure 1988), og rapporten fra det første nordiske økomuseumsseminaret på Samsø i Danmark 1992 (Nymark/Reshaur 1992).

Økomuseumsboka gir introduksjoner ved Marc Maure og Hugues de Varine, og presenterer "historiske» dokumenter som Santiago-erklaringen (1972), artikler om neighbourhood museer fra USA (Kinard), de franske økomuseene, MINOM - Inter- 
60 national Movement for a New Museology, om utstillingen som arbeidsform (Maure, Bengtsson) og om økomuseer i Norge (Gjestrum m.fl.).

I rapporten fra Nordisk Økomuseumsseminar på Samsø 1992 presenterer Marc Maure økomuseumsbegrepet, og det er tekster knyttet til hvert av landene Danmark (Wiberg), Sverige (Hamrin), Finland (Sjöstrand) og Norge (Gjestrum).

En grunnleggende viktig publikasjon er verket om Georges Henri Rivière La muséologie selon Georges Henri Rivière (ed. Hélène Weis 1989), som utkom fem år etter hans død. Her er tekster fra Rivières forelesninger i museologi ved Paris-Sorbonne universitet, biografiske artikler om Rivière og artikler som tar opp utviklingen innen de felt han tok aktivt del, der selvsagt økomuseene er viktige. Boka rommer en fullstendig bibliografi over Rivières publikasjoner.

Mens økomuseene representerer en bestemt museumstype, har miljøene knyttet til begrepet "ny museologi" inkludert en større del av museumsprofesjonen. Et hovedverk for studiet av dette er tobindsantologien Vagues - une anthologie de la nouvelle muséologie (Desvallées, Odile de Bary, Wassermann eds. 1992 vol. 1 og 1994 vol 2). De to bindene rommer på tilsammen 1.100 sider omkr. 80 artikler fra forfattere fordelt på en rekke land, der tekstene dekker viktige sider ved framveksten av nye idéer og museumsmodeller fra de siste 30 år. Til nå er tekstene bare tilgjengelig på fransk. Den canadiske museologen Duncan Cameron arbeider med en engelskspråklig utgave som er planlagt utgitt i 1997.

Hvis vi skal gå videre innenfor de enkelte land, fører det alt for langt her å gi dek- kende kommentarer for alle land. Litteraturlisten nedenfor viser imidlertid at det finnes en omfattende litteratur. Innen Norden er det større publikasjoner fra Vestjyllands Økomuseum i Danmark (Clausen m.fl. 1990), Ekomuseum Bergslagen i Sverige (Hamrin/Rehnberg 1984, Rehnberg 1984, Backlund/Sörenson 1986, Sörenson m.fl 1987) og Toten økomuseum i Norge (Gjestrum 1990).

Den eneste omfattende akademiske avhandling om økomuseene som er blitt utgitt i bokform er Andrea Hauenschilds Neue Museologie (1988), der hun gjør en studie av "nye» museumserfaringer i Amerika: økomuseer i Québec/Kanada, neigbourhood museer i USA og av «museo integral» i Mexico. Det finnes imidlertid flere upubliserte avhandlinger (Babbidge 1977, Charlier van Cutsem 1983, Wiberg 1992).

Etterhvert som substansen i økomuseumsfenomenet har avtegnet seg har også betraktere utenfra formulert sine synspunkter. En av disse er Kenneth Hudson som skriver om Le Creusot i sin Museums of Influence (1987), og mer generelt om økomuseer i flere lengre og kortere artikler på 1990-tallet, der hans artikkel The dream and the reality - 20 years of ecomuseums and ecomuseology fra Museums Journal (1992) må framheves. En annen ganske nylig publisert oversiktsartikkel er ved Dominique Poulot (1994).

Et spesielt problem er knyttet til hva som skal defineres som økomuseumslitteratur og hva som ikke er det. I litteraturlisten er det her gjort en streng avgrensing. Likevel synes det helt nødvendig å ta med ihvertfall noen viktige titler knyttet til museumskritikk og tiltak som oppstod fra samme utgangspunkt som økomusee- 
ne, men fikk litt andre uttrykk. Det gjelder UNESCO-konferansen om museets sosiale rolle i Latin-Amerika (Santiagoerklaringen 1972), neigbourhood museene i USAs storbyer (Kinard 1972, 1985) og Gräv där du står-bevegelsen og arbeidslivsmuseene i Sverige (Lindqvist 1978 og Geijerstam 1992).

Selv om det er en omfattende litteratur som dekkes av bibliografien nedenfor, inneholder den med enkelte unntak bare publikasjoner på engelsk, fransk, tysk og skandinaviske språk. De siste åra har imidlertid økomuseumsidéene fătt en viktig plass også i japansk, kinesisk og russisk museumstenkning. Det vil bli spennende å se hva slags uttrykk idéene får $\mathrm{i}$ disse landene. Litteratur om dette har vi imidlertid ennå $\mathrm{i}$ liten grad tilgang til.

\section{BIBLIOGRAFI}

Almeida-Moro, Fernanda de Camargo e. 1989. An Ecomuseum at a hydroelectric power station, $\mathrm{p}$. 58, illus. Museum; 161. Translated from Portuguese. (Ecomuseu de Itaipu, Brazil) Arcos, Paulina; Malara, Margherita. 1987. Etude comparative des statuts et modes de gestion des écomusées, (Paris), (Ecole du Louvre), (var. pagings). (fre). Monographie proposée par M. Christian Pattyn dans le cadre de l'année de Muséologie, Ecole du Louvre, 1986-1987. Incl. bibl., ann.

Babbidge, Adrian. 1977. Aspects of the Function and Management of Ecomuseum Schemes. University of Leicester.

Barbe, Jean-Michel. 1985. Présence et avenir du passé : Contribution à une problèmatique des nouvelles muséologies, Paris, Ministère de la Jeunesse et des Sports, Institut national d'éducation populaire, p. 55-64. Les Cabiers de l'anima- tion; 51 (fre). Paper presented at the first Atelier international Ecomusées/Muséologie nouvelle, Québec, Oct. 1984.

Bedekar, V. H. 1996. New Museology for India. University of Baroda, India.

Bellaigue-Scalbert, Mathilde. 1981. Industrial archaeology in industrial anthropology: the Ecomuseum of the Community of Le CreusotMontceau-les-Mines, France, p. 228-236, illus. Industrial Archaeology Review; 5, 3 (eng).

Bellaigue-Scalbert, Mathilde.1985. Actors in the real world, p. 194-197, illus. Museum; 148 (fre; also in eng, spa)

Bengtsson, Per. 1976. Mot en öppen institution. Om Riksutställningars uppsökande verksamhet. Svenska Museer 2, p. 43-49, 61. Også gjengitt Gjestrum/Maure 1988: Økomuseumsboka p. 147156.

Boylan, Patrick J.. 1982. The New role of a regional museum service in environmental research, $p$. 21-23. Museums Journal; 82, 1 (eng).

Boylan, Patrick. 1990. "Museums and Cultural Identity", Museums Journal, no. 90/6, p. 29-33

Buch, Carl Egil. 1984. Miljøavdelinger - desentralisert museumsdrift, p. 20-22, illus. Museumsnytt; 33/1 (nor).

Bårtvedt, Randi. 1991. Museet og oppbygging av kunnskap i lokalsamfunnet. Museumsnytt 3-4, p. 15-18.

Bårtvedt, Randi. 1996. Industrisamfunn og kulturarv. Nordisk Museologi 1996/1: 67-72.

Charlier Van Cutsem, Véronique. 1983. L'Ecomusée: perspectives d'un "musée moderne", Louvain, Université catholique, (314) p. (fre). Incl. bibl. Mémoire presenté en vue de l'obtention d'un titre de licence en Histoire de l'Art.

Chiva, Isac. 1986. Georges Henri Rivière: fifty years in the ethnology in France. p. 539-554 Social Science Information; 25, 3.

Chonchol, Maria Edy de. 1985. L'Ecomusée de Haute-Alsace: initiative qui relie la récupération de l'habitat rural à un projet pédagogique, $\mathrm{p}$. 
John Aage GJestrum

313-318, illus. Meridies; 2 (fre).

Clausen, Kim and m.fl. 1990. Vestjyllands

Økomuseum - landskab, kultur og turisme. Skjern,

Cnattingius, Nanna. 1984. Ekomuseer, p. 28-31,

illus., maps. Kulturminnesvård; 5 (swe).

Cnattingius, Nanna; Wikander, Marita; Antell, Elina; Cnattingius, Lars; Edgren, Bengt; Flink, Gerhard; Raihle, Jan; Lundgren, Olle; Jonsson, Marita; Hemmendorff, Ove. 1989. Kultur och turism, p. 1-24, illus. Kulturmiljövård; 2 (swe). Incl. 9 articles.

Collin, Gérard. 1981. L'Ecomusée du MontLozère; système d'interprétation d'un espace granitique, p. 17-21, illus. Musées et collections publiques de France; 150 (fre).

Collin, Gérard. 1984. L'Ecomusée du MontLozère, p. 23-25, illus. Sites et Monuments; 106 (fre).

Collomb, Gérard; Renard, Yves. 1982. On MarieGalante (Guadeloupe) : a community and its ecomuseum, p. 109-113, illus. Museum; 34, 2 (eng; also in fre, spa).

Colloque "Musée et environnement» organisé par l'ICOM, Bordeaux, Istres, Lourmarin, Paris, $25-$ 30 septembre 1972: Extrait des conclusions, 1973. p. 119-120. Museum; 25, 1/2 (fre; also in eng).

Conradson, Birgitta; Fägerborg, Eva. 1982. Det Totala museet. Om ekomuseet i Le Creusot, p. 37-40, illus., map. Svenska Museer; 1 (swe).

Côté, Michel, ed. 1992. Museological trends in Québec. Québec,

Cruz-Ramirez, Alfredo. 1985. The Heimatmuseum: a perverted forerunner, p. 241-244, illus. Museum; 148 (fre; also in eng, fre).

Dalibard, Jacques. 1984. What is an eco-museum? Ottawa, The Heritage Canada Foundation, p. 24, illus. Canadian Heritage; Oct.-Nov. (eng).

Davallon, Jean (dir.). 1986. Claquemurer, pour ainsi dire, tout l'univers: la mise en exposition, Paris, Editions du Centre Georges Pompidou, CCI, 302 p. Alors; 10 (fre). Incl. bibl.
Découvrir les écomusées, Rennes, Musée de Bretagne, 1984. 48 p, illus. (fre). Exposition realisée à l'occasion d'une rencontre sur les écomusées au Musée de Bretagne, Rennes. Incl. bibl.

Denis, Emily. 1971. A Museum for the people, Report from the Seminary on Neighborhood Museums at the Muse, New York.

Desrosiers, Guy; Lafleur, Gerald. 1981. La Maison du Fier Monde, 35 p, illus. Montréal (fre).

Desvallées, André. 1981. Ecomusées, Encyclopedia Universalis France S.A., p. 421-422. (fre). From : Universalia 1980, Annual Supplement to the "Encyclopedia Universalis". Paris.

Desvallées, André. 1985. L'Ecomusée: musée degré zéro ou musée hors les murs? p. 84-85, illus. Terrain. Carnets du Patrimoine ethnologique; 5. (fre).

Desvallées, André. 1985. New Museology. 1985, Stockholm, Museum of National Antiquities (for the) ICOM International Committee for Museology, p. 65-69. Museological News = Nouvelles muséologiques; 8 (fre; also in eng). Paper presented at the ICOM Consultative Committee, Paris, July 1 st 1985.

Desvallées, André. 1992. Museology and cultural identity. Papers in Museology, 1, Umeå p. 50-77

Desvallées, André; de Bary, Marie Odile; Wasserman, Françoise. 1992-1994. Vagues: une anthologie de la nouvelle muséologie I-II. Editions W, Macon (engelsk utg. utgis i Canada i 1997).

Domeij, Ingrid. 1984. Museet i framtiden - visioner, roller, resurser, p. 8-10, illus. DIK-forum; 8 (swe).

Dubois de Montreynaud, H.; La Soudière, M. de; Boulet, T.. 1988. L'Ecomusée de la Margeride: Musée des champs, musée aux champs? p. 113119, illus. Terrain. Carnets du patrimoine ethnologique; 11 (fre).

Dybeck, Torsten. 1987. Funderingar kring Ekomuseum Bergslagen. Svenska Museer (2): 2021.

Dybeck, Torsten. 1987. Ekomuseum Bergslagen än 
en gång. Svenska Museer (3): 7-8.

Ecomusée de la Communauté du Creusot Montceaules-Mines, Stockholm, Riksutställningar, 1980. 12 p., illus. (swe).

Ecomusées du Québec, Ottawa, 1985. p. (9-15). Bulletin. Association des écomusees du Québec; 1, 3 (fre).

Ecomusées en France, Actes des premières rencontres nationales des écomusées. 1987. Grenoble.

Enerstvedt, Åse. 1989. Økomuséer, nytt navn på gammel idé? Kulturnytt (2): 15 (1s.).

Engström, Kjell. 1981. Svenskt fjällmuseum; forrslag till uppbyggnad av ett svenskt fjällmuseum $i$ Jokkmokk, Länsstyrelsen i Norrbottens Län Planeringsavdelningens rapportserie; 18, Luleå, 143 p., illus., maps. (swe).

Engström, Kjell. 1985. The Ecomuseum concept is taking root in Sweden, p. 206-210, illus. Museum; 148 (eng; also in fre, spa).

Engström, Kjell. 1986. Har vi ekomuseer i Sverige? p. 5-8, illus. Svenska Museer; 2-3 (swe). Incl. bibl.

Ett nytt "eko-museum» $i$ Sydfrankrike: parc naturel régional de Camargue, Riksutställningar, Stockholm, 1980. 15 p., ill. (swe).

Evrard, Marcel. 1980. Le Creusot-Montceau-lesMines: the life of an ecomuseum, assessment of ten years, p. 226-234, ill. Museum; 32, 4 (eng).

Ford, Olwen. 1985. Melbourne's Living Museum of the West: a museum without walls, (s.1.), CAMA, p. 19-26, illus. Museums Australia; Sept. (eng). Paper presented at the First National Conference of CAMA, University of Adelaide, 15-18 October 1984.

From Burgundy to Bergslagen. Papers presented at an international seminar May 30-31 1996 (Ulla Keding Olofsson, Ewa Bergdahl, Maria Björkroth, David de Haan, Örjan Hamrin, Kenneth Hudson, Hugues de Varine). Riksutställningar, Stockholm (eng, swe).

Frøiland, Øystein. 1975. Økomuseet: tverrvitenskap i praksis, p. 97-100, ill. Museumsnytt; 24, 2 (nor). Fuller, Nancy J. 1992. The Museum as a Vehicle for
Community Empowerment: The Ak-Chin Indian Community Ecomuseum Project. In: Museums and Communities: The Politics of Public Culture. Ivan Karp and Christine M. Kreamer et al, eds. Washington, DC: Smithsonian Institution.

Ganslmayr, Herbert. 1986. Keynote-Paper. Seminar 'Integrating Museums into the Life of the Community', Seoul, 1986, Ubersee-Museum, Bremen, 26 p. (eng). Incl. bibl.

Gariepy, Céline. 1986. L'Ecomusée de la HauteBeauce et le développement communautaire. Mémoire présenté pour l'obtention du grade de maîtrise en Aménagement du Territoire et Développement régional. Incl. bibl. and statistical data. Montréal, Université de Montréal, 103 p. (fre).

Geijerstam, Jan af. 1990. Arbetets historia i Sverige. En guidebok til museer och miljöer. Norrköping.

Geijerstam, Jan af 1992. Ekomuseer i rörelse. Kulturmiljövård (4): 62-63.

Gjestrum, John Aage; Maure, Marc. 1986. Nouvelle muséologie: traditions et perspectives nordiques $-d u$ musée de plein-air à l'écomusée / les minorités des régions arctiques. 3e Atelier international de nouvelle muséologie, Toten, MINOM, 66 p., illus. (various texts in eng, fre).

Gjestrum, John Aage (ed.); Maure, Marc (ed.). 1988. Økomuseumsboka - identitet, okologi, deltakelse: Ei arbeidsbok om ny museologi, Tromsø, Tromsø Museum (for) Norsk ICOM, 192 p., illus. (various texts in nor, eng). Incl. bibl.

Gjestrum, John Aage and Maure, Marc 1989. Arbeidarkulturen på museum. Syn og Segn (2): 157-164.

Gjestrum, John Aage. 1984. Seminaret økologi og identitet; økomuseumstanken har slått rot i Norge, p. 9-14, illus. Museumsnytt; 33, 2 (nor).

Gjestrum, John Aage. 1985. 1900-tallet - snart forrige århundre. Økomuseet - et bindeledd mellom fortid, nåtid og framtid. TOTN arrbok 1985, 6-15. Gjestrum, John Aage. 1989. Istedet for museumsbygg? Økomuseet - det åpne museet. Museumsnytt (1-2): 48-52. 
64 Gjestrum, John Aage. 1990. The ecomuseum good news in Africa? ICOFOM: Museums and heritage preservation, Zambia, Zambia Heritage News Magazine.

Gjestrum, John Aage. 1990. Økomuseet - for lokalsamfunnet i verden. TOTN arrbok 1990, 6-15.

Gjestrum, John Aage. 1992. Økomuseumsperspektivet - en viktig innfallsvinkel og utfordring i den norske museumssituasjonen. In: Nymark, Lis and John Reshaur. (1992). Rapport fra Nordisk Økomuseumsseminar. Økomuseum Samsø. p. 47-61.

Gjestrum, John Aage. 1993. Fra folkemuseum til økomuseum. Økomuseumsbegrepet - en fornyelse av museumsinstitusjonen og et viktig instrument for lokalsamfunnet. Heimen 1993:1, s. 3045.

Gjestrum, John Aage. 1994. Lokalmuseer og museumsprofesjonalitet. Nordisk Museologi 1994:1, s. 75-82.

Gjestrum, John Aage. 1995. Norwegian experiences in the field of ecomuseums and museum decentralisation. In: Schärer, Martin R. (ed.)

Symposium Museum and Community II, Stavanger, Norway July 1995. ICOFOM Study Series Vol. 25. Vevey. p. 201-212.

Goujard, Marc. 1982. Fourmiès et sa région. $1827-$ 1980. L'héritage, Fourmiès, Ecomusée de la région Fourmiès-Trelon, 69 p, illus. (fre).

Granström, Majlis. 1991. Det lokala museet - närkontakt av tredje graden. Norbottens Museums Arsbok 1991. Luleå, 54-63.

Gregersen, Gunnar. 1981. Arbeiderkultur på museum. Museumsnytt (3): 10-13.

Grodwohl, Marc. 1987. L'Ecomusée de HauteAlsace, p. 38-43, illus. Musées et collections publiques de France; 177 (fre).

Grodwohl, Marc. 1987. L'Ecomusée de HauteAlsace, p. 100-109, illus. Terrain. Carnets du Patrimoine ethnologique; 9 (fre).

Guibal, Jean. 1984. La Cultura tecnica e industriale nei musei ed ecomusei francesi, p. 5. Scuola offi- cina; (Bologna, Istituto Aldini-Valeriani), 3, 1-3) (ita).

Hamrin, Örjan m.fl. (eds). 1996. Museet som makt och motstaind. Festskrift till Erik Hofrén 10 april 1996. Norrköping.

Hamrin, Örjan; Rehnberg, Hans. 1984. Ironbridge Gorge Museum, p. 31-33, illus.

Kulturminnesvård; 5 (swe).

Hamrin, Örjan. 1992. Ekomuseitankar i Sverige,.in: Nymark, Lis and John Reshaur. Rapport fra Nordisk Økomuseumsseminar.

Økomuseum Samsø. p. 16-18.

Harvey, Emily Dennis and Bernard Friedberg, ed. 1971. A museum for the people. A report of proceedings at the Seminar on Neighborhood Museums, held November 20, 21 and 22, 1969, Brooklyn, New York. New York, Arno Press.

Hasegawa, Sakae. 1987. Amerita no toshi to bijutsukan. "Gendai bijutsu no shakaiteki kory". Atarashii etoroji-mjujamu tenkai, Tokyo, Nihon hakubutsutan kyokai, p. 19-25, illus.

HakuLutsukan kenkyu; 22, 1 (jap).

Hasegawa, Sakae. 1987.21 seiki ni mukete no bijutsukan kakumei. Pari de jitsugen no biggu purojekuto. Eco-musée no tetsugaku tsuranutu, Tokyo, Nihon hakubutsukan kyotai, p. 2-8, illus. Hakubutsukan kenkyu; 22, 10 (jap).

Hauenschild, Andrea. 1988. Neue Museologie: Anspruch und Wirtlichkeit anhand vergleichender, Fallstudien in Kanada, USA und Mexiko. Bremen, Ubersee-Museum, illus. (Veröffentlichungen aus dem Ubersee-Museum Bremen. Reihe D; 16) (ger). Incl. bibl. Doctoral thesis, Fachbereich Kulturgeschichte und Kulturkunde der Universität Hamburg angenommen, under the dir. of Prof. Jurgen Jensen and Dr. Herbert Ganslmayr, 3. Februar 1988. Det finnes også en engelsk versjon av manuskriptet: Hauenschild, Andrea. (1988). Claims and reality of the new museology. Hamburg.

Haug, Ragnhild. 1990. Økomuseum Skagerrak : fra jordbruk og jernverk til byer og båter. 
Fortidsvern. nr 2, p. 5-8.

Hauge, Tore. 1989. Desentraliserte museumsanlegg i Nord-Troms. Museumsnytt 1-2, p. 52-55.

Hauglid, Anders Ole. 1985. Nord-Troms Museum, p. 70-73, illus. Museumsnytt; 34, 3-4 (nor).

Hinten, Wassilia von. 1982. L'Ecomusée ; ein museologisches Konzept zur Identität von und in Raumen, Stuttgart, Deutsche Gesellschaft für Volkskunde, p. 70-76. Zeitschrift fiur Volkstunde; 78) (ger).

Hinten, Wassilia von. 1985. Zur Konzeption des "Ecomusée» in Frankreich, Rzeszow, Kra]owa Agencja Wydawnicza (for) Muzeum Budownictwa Ludowego w Sanoku, p. 43-64, illus. Acta scansenologica; 3 (ger; abstr. in pol, eng). Incl. bibliogr. notes.

Hofrén, Erik. 1979. Tankar på en historieverkstad. Falun, Dalarnas museum.

Holst, Lars. 1979. Creusot. Mål, målgrupper og struktur. Dansk tidsskrift for museumsformidling 4, s. 52-60.

Holton, Michael. 1973. Carnegie United Kingdom Trust, p. 113. Museums Journal; 73, 3 (eng). (Paper presented at the Annual Conference of the Museums Association, Dundee, 1973. Session 3: Environmental awareness: Scotland).

Hubert, Francois. 1985. Ecomuseums in France: contradictions and distortions, p. 186-190, illus. Museum; 148 (fre; also in eng, spa).

Hubert, Francois. 1986. Faguo de shengtai bowuguan : maodun he jibian Beijing, Zhongguo bowuguan xuehui, p. 7882. Zhongguo bownguan; 4 (chi). Translated from French. Text published in: Museum, Paris, Unesco, n. 148, 1985, p. $186-$ 190.

Hubert, Francois; Maillard, Jean-Luc; Veillard, Jean-Yves. 1987. Ecomusée du pays de Rennes : la Bintinais, Rennes, Ecomusée du pays de Rennes, 48 p, illus. (fre).

Hudson, Kenneth. 1991. Letter from Gratangsbotn. Museums Journal (April): 20. Hudson, Kenneth. 1992. The Dream and the
Reality. 20 years of ecomuseums and ecomuseology. Museums Journal (April): 27-31.

Hård, Gudrun. 1977. Museimiljöer, Stockholm, p. 9-12, ill. Artitekttidningen; 9.

ICOM General Conference, 9th, Papers from the 9th General Conference of ICOM Grenoble 1971.

Paris 1972 .

ICOM. Symposium "Museums and environment", Bordeaux, Istres, Lourmarin, Paris, 1972, Final report and conclusions. Paris, ICOM, 1972. 6 p. (eng; also in fre). Symposium held from 25 to 30 September 1972, at the invitation of the French Ministry for the Environment and the French National Committee of ICOM.

ICOM General Conference, 10th, Copenhagen, Denmark, 1974, The museum and the modern world: Papers from the Tenth General Conference of Icom. Oxford, Parchment for ICOM, 1975. 119 p., ill.

ICOM International Committee for Training of Personnel. Joint colloquium, London, 1983, Methodology of museology and professional training. Museum territory - society ; new tendencies, new practices. Addenda 2. Stockholm, Museum of National Antiquities (for) ICOFOM, 1983. 36 p. ICOFOM Study Series; 4 (eng).

ICOM International Committee for the Training of Personnel. ICOM International Committee of Museology. Joint colloquium, London, 1983, Methodology of museology and professional training. Museum territory - society; new tendencies, new practices. Addenda 3. Stockholm, Statens Historiska Museum (for the) ICOM International Committee for Museology, 1983. (n.p.). ICOFOM Study Series; 5 (various texts in eng, fre).

Images of the ecomuseum, Paris, Unesco, 1985. p. 182-244, illus. Museum; 148 (same text in eng, fre, spa).

Janer, Eulalia. 1976. El ecomuseo de "plein air» de Landes-Gascogne, Barcelona, p. 78-81, ill.

Estudios Pro Arte; 5 (spa). 
JOHN AAgE GJESTRUM

66 Jeannot-Vignes, Bernard. 1976. Collecting material for an ethnographical exhibition: an experiment conducted by the "Ecomuseum» of the Urban Community of Le Creusot-Montceau-les-Mines, p. 162-169, ill. Museum; 28, 3 (eng).

Joubert, Alain. 1984. Les Ecomusées de France, Le Trait, Parc naturel régional de Brotonne, $13 \mathrm{p}$, illus., maps. (fre).

Journée d'étude sur les écomusées, Montréal, Canada, 1983, Journée d'étude sur les écomusées, Université du Québec à Montréal, le 26 mai 1983; document de travail. Varine-Bohan, Hugues de; Mayrand, Pierre. Montréal, Université du Québec, Groupe de recherche en patrimoine, 1983. (40)p. (fre). Incl. list of participants.

Kinard, John R. 1972. Anacostia kvartermuseum. Museum (oversatt i Dansk Tidsskrift for Museumsformidling) (1977): 99-104.

Kinard, John R.. 1985. The Neighbourhood museum as a catalyst for social change, p. $217-$ 223, illus. Museum; 148 (eng; also in fre, spa). Incl. bibl.

Kinard, John. 1968. The Smithsonian's Anacostia Neighborhood Museum, Curator no. XI/3. p. 190-205.

Kinard, John. 1972. To meet the Needs of today's Audience, Museums News, Washington.

Kinard, John. 1972. Intermediaries between the Museum and the Community, Papers from the 9th General Conference of ICOM Grenoble 1971, p. 150-156, Paris.

Konaré, Alpha Oumar. 1983. Towards a new type of "ethnographic» museum in Africa. Museum; 35(3): 146-149.

Konaré, Alpha Oumar. 1985. Ecomuseums for the Sahel : a programme p. 230-236, illus. Museum; 148.

Konaré, Alpha Oumar. 1987. Afrikansk museologi behöver en ny teori. ICOFOM conference, Espo, Finland, Svenska Museer; 5-6 p.42-43.

L'approche muséologique du milieu de vie, un outil pour les parcs, Fédération des parcs naturels de
France, Conférence permanente des parcs, Paris, 1978. (48) p. (fre).

Laine, Christian. 1985. Reflexioner kring två figurer och ett begrepp. Svenska Museer (3): 3-6.

Les parcs naturels régionaux et le patrimoine ethnologique, Fédération des parcs naturels de France, Paris, 1979.36 p., ill. (fre).

Levesque, Carole. 1975. Le musée éclaté, p. 18-21, ill. Gazette; 8, 3 (fre).

Lindqvist, Sven. 1978. Gräv där du står. Hur man utforskar ett jobb. Stockholm,

Lorenzo, Jose Luis; Rincon M., Carlos; Camara B., Fernando; Lacouture, Felipe. 1984. Ecomuseo, region Morelos, (Mexico D.F.), Secretaria de Desarrollo Urbano y Ecologia (SEDUE), 51 p, illus. (spa). Incl. in ann. «Rutas turisticas».

Lozada, Javier; Martini, Tirso. 1987. Museo de la isla de Cozumel, (The authors), 64 p., illus. (spa).

Lundgren, Britta. 1990. Ecomusée le Creusot Montceau-les mines - 16 år efteråt! Svenska Museer (1): 19.

Maroevic, Ivo. 1984. Od muzeja na otvorenom do eko-muzeja, (From the open-air to eco-museum), Zagreb, Muzejski dokumentacioni centar, p. 1819. Informatica museologica; 3 (cro; abstr. in eng). Maure, Marc. 1977. Kultur og nærmiljø - nye veier i museumsverdenen. Museumsnytt (4): 147-151.

Maure, Marc. 1978. Thoughts on a new function of the museum. ICOM Education (8): 32-34.

Maure, Marc. 1984. Museum - identitet, økologi, deltakelse,. p. 5-8, illus. Museumsnytt; 33, 2 (nor).

Maure, Marc. 1985. Ecomusées et musées de pleinair: l'exemple norvégien. Musées (8):27-29.

Maure, Marc. 1988. Identitet, økologi, deltakelse om museenes nye rolle. I Gjestrum/Maure: Økomuseumsboka p. 16-32.

Maure, Marc. 1988. Ny museologi - en internasjonal bevegelse organiserer seg. I Gjestrum/Maure: Økomuseumsboka p. 130-134.

Maure, Marc. 1991. Fra ego til øko? Om museene i miljøalderen. Museumsnytt 1991/1: 22-25. 
Maure, Marc. 1992. "Økomuseum» - om et nytt begrep i museumsverdenen,.in: Nymark, Lis and John Reshaur. Rapport fra Nordisk Økomuseumsseminar. Økomuseum Samsø. p. 815.

Maure, Marc. 1994. GHR- Georges Henri Rivière og folkemuseets genesis i Frankrike. Nordisk Museologi 1994/2 121-131.

Mayrand, Pierre. 1980. Le Métier d'inventeur de musées, p. 13-15, illus. Musées; 3, 4 (fre).

Mayrand, Pierre. 1984. Enracinements de la nouvelle muséologie au Québec, p. 32-37, illus. Muse; 2, 1, Spring (same text in eng, fre).

Mayrand, Pierre. 1985. The new museology proclaimed. Museum 148, p. 200-201, vedlegg: Declaration of Québec: Basic principles for a new museology.

MINOM. Atelier international, 2nd, Lisboa, 1985 , Deuxième atelier international de nouvelle muséologie: Musées locaux, nouvelle muséologie. Lisboa, (MINOM), 1985. (18) p. (por).

Miralles, Francesc; Janer, Eulalia. 1975. El ecomuseo; renovacion museologica, Barcelona, p. 8691, ill. Estudios pro Arte; 3 (spa).

Moniot, Francois. 1973. The Ecomuseum of Marquèze, Sabres: part of the Regional Natural Park of the Landes de Gascogne, p. 79-84, Museum; 25, 1/2 (eng). Incl. bibl.

Morel, Alain. 1983. Ecomusée de la région de Fourmiès-Trelon, Paris, Mission du Patrimoine ethnologique, p. 46-47, illus. Terrain. Carnets du Patrimoine ethnologique; 1 (fre).

Musée et nouvelle muséologie, Montréal, Société des musées québecois, 1985. 34 p, illus. Musées; 8,1 (fre).

Nabais, Antonio Jose C. Maia. 1984. The Municipal Museum of Seixal: an ecomuseum of development, p. 71-74, illus. Museum; 142 (eng; also in fre, spa).

Nabais, Antonio Jose. 1985. Development of ecomuseums in Portugal, p. 211-216, lllus. Museum; 148.
Nicolas, Alain. 1985. Nouvelles muséologies,

Marseille, MNES, 192 p, illus.(fre). Incl. bibl.

MNES - Muséologie Nouvelle et

Expérimentation Sociale (France).

Nouvelle muséologie, 1991. Musées 13/4: 5-32

Nymark, Lis and John Reshaur. 1992. Rapport fra

Nordisk Økomuseumsseminar. Økomuseum Samsø.

O Territorio, o homen, a historia: Catalogo-Guia,

Seixal, Camara municipal do Seixal, Ecomuseu municipal do Seixal, 1987. 49 p, illus. (por).

Introduction by Antonio Jose C. Maia Nabais. Incl. bibl.

Olcina, Paulette. 1986. Land - Kulturarv Samhälle. Kring ekomuseets uppkomst, p. 2-4. Svenska Museer; 2-3 (swe). Paper translated from French, presented at the Seminar 'Territory Heritage - Community Ecomuseums: man and his environment', Oaxtepec, Mexico, 1984.

Orander, Ian. 1985. Ekomuseum Västerbergslagen: Järnets historia och kulturturism, p. 11-13, illus. DIK-forum; 10 (swe).

Pabon Flores, Francisco. 1980. The Montoso Ecomuseum of the Rain Forest and the natural history of Puerto Rico, p. (77-85). ICOM Natural History Museums Newsletter; 6 (eng; abstr. in fre).

Pazdur, Jan. 1984. Ekomuzeum aglomeracji staropolskiej w Starachowicach - zamysl i propozycje, Warszawa, Osrodek dokumentacji zabytkow, p. 39-50, illus. Nuzealnictwo; 28-29 (pol; abstr. in fre).

Persson, Eva. 1978. Allas museum : Om Ecomuseum i Le Creusot i Frankrike, p. 3-7, illus. Form; 74, 8 (swe).

Poulot, Dominique. 1994. Identity as SelfDiscovery. The Ecomuseum in France. In Sherman, Daniel J. and Rogoff Irit (eds.) Museum Culture. Histories, Discourses, Spectacles. Minneapolis p. 66-85.

Querrien, Max. 1985. Taking the measure of the phenomenon, p. 198-199. Museum; 148 (fre; also in eng, spa). 
Rehnberg, Hans. 1984. Ekomuseum Bergslagen i Västmanland, Västerås, Länsstyrelsen, 41 p, illus., maps. Länsstyrelsen $i$ Västmanlands län informerar; 1 (swe; abstr. in eng).

Rehnberg, Hans. 1984. Två planerade ekomuseer i Bergslagen, p. 16-20, illus. Svenska Museer; 1 (swe).

Rehnberg, Hans; Hamrin, Örjan. 1984. Ekomuseum Västerbergslagen. Utredning och forslag, Falun, Dalarnas Museum, 60 p, illus. (Dalarnas Museums serie av rapporter; 14) (swe). Incl. bibl.

Renard, Yves. 1985. Patrimoine industriel et développement à partir de deux expériences aux Petites Antilles (Marie-Galante et Sainte-Lucie). Paris, CNRS, p. 80-86. (fre). L'Etude et la mise en valeur du patrimoine industriel.

Rencontres nationales des écomusées, 1 st, L'Isle d'Abeau, France, 1986, Ecomusées en France. Actes des premières rencontres nationales des écomusées. (Grenoble), Agence régionale d'ethnologie RhoneAlpes, 1987. 268 p. (fre).

Répertoire: Le Québec des écomusées, Montréal, Québec, Association des Ecomusées du Québec, 1987. 30 p., illus. (fre).

Rivard, René. 1984. Opening up the museum or Toward a new museology : ecomuseums and "open" museums, Que le musée s'ouvre... ou Vers une nouvelle muséologie : les écomusées et les musées 'ouverts', Québec, René Rivard, 117 p. (fre; also in eng). Stensil, forarbeid til bok.

Rivard, René. 1985. Ecomuseums in Québec. p. 202-205, illus. Museum; 148 (fre; also in eng, spa).

Rivière, Georges Henri. 1971. Le musée de pleinair des landes de Gascogne, Ethnologie française, 1.

Rivière, Georges Henri. 1972. Un Musée de l'espace et du temps, Florac, Parc national des Cévennes, p. 25-29, illus. Cévennes; 1 (fre).

Rivière, Georges Henri. 1973. The museum as a monitoring instrument: role of museums of art and of human and social sciences, p. 26-44, ill. Museum; 25, 1/2 (eng).

Rivière, Georges Henri. 1980. Le Patrimoine rural dans la France d'hier et d'aujourd'hui, p. 1-5, illus. Aménagement et nature; 58 (fre). Entretien avec Roland Bechmann.

Rivière, Georges Henri. 1981. Parc naturel régional des Landes de Gascogne, Marquèze écomusée de la grande lande: Allocution prononcée (...) lors des journées d' étude "Patrimoine et développement» organisées à 1 'occasion de l'Année du Patrimoine, les 4 et 5 octobre 1980, Dax, Ducasse-Duhon, 14 p., illus. (fre). Extrait du Bulletin de la Société de Borda.

Rivière, Georges Henri. 1985. The Ecomuseum an evolutive definition, p. 182-183, illus. Museum; 148 (fre; also in eng, spa), oversatt til svensk i Svenska Museer 1986/4-5: 32.

Rivière, Georges Henri. 1986. Shengtai bowuguan yige jinhua de dingyi, Beijing, Zhongguo bowuguan xuehui, p. 75 . Zhongguo bowuguan; 4 (chi). Translated from French. Text published in : Museum, Paris, Unesco, n. 148, 1985, p. 182183.

Rivière, Georges Henri; Collin, Gérard. 1974. Programme d'un écomusée du Mont Lozère dans le cadre du Parc national des Cévennes, présenté aux Autorités du Parc, Florac, 32 p., ill. (fre).

Rivière, Georges Henri; Collin, Gérard. 1977. Parc national des Cévennes: écomusée du Mont Lozère. Proposition pour un programme. Unité agro-pastorale de TrouLat, Florac, Parc national des Cévennes, 27 p., plans. (fre).

Rogan, Bjarne. 1987. Franske økomuseer. Et levedyktig kultureksperiment - men hva er de egentlig? Dugnad (1): 19-29.

Rogan, Bjarne. 1984. Regionalparker - en grobunn for anvendt kulturhistorisk forskning i Frankrike, p. 24-28, illus. Museumsnytt; 33, 4 (nor).

Rosander, Göran (ed.) 1991. Karl-Erik Forsslund: Författaren, folkbildaren, hembygdsvårdaren (Dalarnas hembygdsbok 1991). Falun. 
Rosander, Göran. 1995. Karl-Erik Forsslund pionjär inom hembygdsvården. Nordisk Museologi 1995/1 117-124.

Rosander, Lennart. 1984. Skärgårdsmuseum i Oxelosund - natur- och kulturhistoria under samma tak, p. 32-34, illus. Svenska Museer; 2 (swe).

Rutas patrimoniales del Ecomuseo Morelos (Mexico), (s.l.), SEDUE, (s.d.). 49 p. (spa).

Santiago-erklaringen. 1972 1. Basic principles of the integral museum. 2. Resolutions adopted by the round table of Santiago (Chile). 3.

Recommendations presented to Unesco by the round table of Santiago (Chile). 4. List of participants ... 5. Museums associations; national committees ... 6. Table of museums in Bolivia, Paris, Unesco, 1973. p. 197-202, ill. (Museum; 25, 3) Også trykt i Gjestrum/Maure 1988:

Økomuseumsboka s. 67-74.

Secretaria de Desarrollo Urbano y Ecologia (SEDUE). Seminar, Oaxtepec, Mexico, 1984, Memoria del Seminario Territorio, Patrimonio, Comunidad.

Sennerfeldt, Per, ed. 1996. Ekomuseum Bergslagen 10 àr 1996. Människa. Miljö. Landskap. Smedjebacken,

Silvester, J.W.H.. 1975. The fragmented museum project at Le Creusot, p. 83-84, ill. Museums Journal; 75, 2 (eng).

Sjöstrand, Peter. 1992. Ekomuseitankar i Finland, in: Nymark, Lis and John Reshaur. Rapport fra Nordisk Økomuseumsseminar. Økomuseum Samsø. p. 26-28.

Skadsem, Morten. 1993. 1980-åra - de nye økomuseene. (Sør-Varanger Museum). Museumsnytt, 2, p. 31-33.

Sofka, Vinos (ed.). 1983. Museum - Territory Society. New tendencies / New practices.ICOM International Committee for Museology. Annual Meeting, 6th, London, 1983, Stockholm, ICOFOM, Museum of National Antiquities, 60 p. ICOFOM Study Series; 2 (various texts in eng, fre).
Sousa Lara, Luis Filipe de. 1979. Contribution for the setting up of an ecological museum of agriculture in Portugal, Praha, Association internationale des musées d'agriculture, p. 92-98. Acta museorum agriculturae; 14, 1-2 (eng).

Stevenson, Sheila. 1981. New reference points : developing an acquaintance with new museum directions in Québec, Report submitted to the Canadian Museums Association in fulfilment of the conditions of the bursary program. Halifax, Nova Scotia Museum, 18 p. (eng).

Stevenson, Sheila. 1982. The Territory as museum : new museum directions in Québec, p. 5-16, illus. Curator; 25, 1 (eng).

Strybol, Jan. 1975. Actieprogramma voor een nieuwe museumpolitiek, Brussel, p. 16-17, ill. Open deur; 7, 9 (fle).

Sydhoff, Beate. 1986. Om ursprungsbefolkningar och museer, p. 18-19, illus. Svenska Museer; 4-5 (swe).

Symposium 'Museum and Environment', organized by ICOM, Bordeaux, Istres, Lourmarin, Paris 25-30 September 1972, Paris, Unesco, 1973. p. 119-120. Museum; 25, 1/2 (eng).

Sörenson, Ulf; Backlund, Ann-Charlotte. 1986. Järn bryter bygd. Ekomuseum Bergslagen berättar $i$ landskapet, Falun, Ekomuseum Bergslagen, 96 p, illus. (swe; abstr. in eng). Incl. map.

Tall, Mahanta. 1983. Projet de musee éclaté de plein air de Nouakchott, Paris, Unesco, 31 décembre 1983. 18 p. (Action internationale contribuant aux activités des Etats membres pour la préservation et la mise en valeur des biens culturels) (fre).

Teruggi, Mario E. 1973. The round table of Santiago (Chile), p. 129-133. Museum; 25, 3 (spa).

Tucoo-Chala, Jean. 1985. Ecomusées, p. 41-45, illus. Sites et Monuments; 109 (fre).

Varine-Bohan, Hugues de. 1973. A 'fragmented' museum: the Museum of Man and Industry, Le Creusot-Monceau-les-Mines, p. 242-249, ill., maps. Museum; 25, 4 (eng). (Norsk oversettelse i 
Gjestrum/Maure. 1988. Økomuseumsboka, p. 90101).

Varine-Bohan, Hugues de. 1976. The modern museum: requirements and problems of a new approach, p. 130-143, ill. Museum; 28, 3 (eng).

Varine, Hugues de. 1976. The museum in the fourth dimension. ICOM-CECA, Umeå,

Varine-Bohan, Hugues de. 1978. L'Ecomusée. p. 28-40, ill. Gazette; 11, 2 (fre). (Norsk oversettelse i Gjestrum/Maure. 1988. Økomuseumsboka, p. 104-122).

Varine-Bohan, Hugues de. 1985. The Word and beyond, p. 185. Museum; 148 (fre; also in eng, spa).

Varine-Bohan, Hugues de. 1986. Shentai bowuguan - yici yi qita, Beijing, Zhongguo bowuguan xuehui, p. 76-77. Zhongguo bounguan; 4 (chi). Translated from French. Text published in : Museum, Paris, Unesco, n. 148, 1985, p. 184 185.

Varine, Hugues de. 1987. O Tempo social, Rio de Janeiro, Livraria Eca Editora, 207 p., tables. (Colecao Eleutherias; 3) (por). Traducao e coordenacao Fernanda de Camargo-Moro e Lourdes Rego Novaes.

Varine, Hugues de. 1988. Rethinking the Museum Concept. Foredrag ved ICOM/UNESCOs konferanse om museer og verdens urbefolkninger $\mathrm{i}$ Jokkmokk, Sverige juni 1986. In Gjestrum/Maure: Økomuseumsboka, p. 33-40.

Varine, Hugues de. 1988. Skandinavias plass i ny museologi. Foredrag ved MINOMs 3. internasjonale arbeidsseminar, Toten, Norge sept. 1986. In Gjestrum/Maure: Økomusetumsboka, p. 41-46.

Varine, Hugues de. 1988. New museology and the renewal of the museum institution. MINOMs 3 . internasjonale arbeidsseminar, Toten, Norge sept. 1986. In Gjestrum/Maure: Økomuseumsboka, p. 62-66.

Varine-Bohan, Hugues de. 1991. L' Initiative communautaire: Recherche et expérimentation, Nacon, Ed. W; Savigny-le-Temple, MNES, 265 p.
Collection Museologia) (fre). Publié en portugais (bresilien) sous le titre "O tempo social", moins les chapitres spécifiquement muséographiques.

Varine, Hugues de. 1994. ARVET - en källa till en lokalt förankrad och lokalt förvaltad utveckling. Ekobladet (3): 2-3.

Varine, Hugues de. 1996. Lokalmuseet som process. Nordisk Museologi 1996/1: 61-66.

Vestheim, Geir. 1994. Museum i eit tidsskifte. Oslo. Vinsrygg, Synnøve. 1980. Det integrerte museum, p. 187-192, ill. Museumsnytt; 29, 4.

Walsh, Kevin. 1992. The Representation of the Past. London.

Weis, Hélène (ed.). 1989. La muséologie selon Georges Henri Rivière. Paris.

Wiberg, Lilly Ruth. 1992. Økomuseumstanker i Danmark,.in: Nymark, Lis and John Reshaur. Rapport fra Nordisk Økomuseumsseminar. Økomuseum Samsø. p. 19-25.

Wiberg, Lilly Ruth. 1992. Økomuseet - idé og realisation: En undersogelse af det franske okomuseums baggrund og udvikling. København, Mag. art. spec. indiv.

Wikan, Steinar. 1985. Mitt Museum. Sør-Varanger Museum, p. 6-9, illus. Pedimus; 3 (nor).

Ågren, Per-Uno. 1984. De nya museerna - närmuseerna? p. 18-19. Svenska Museer; 2 (swe).

\section{NOTE}

Bibliografien hadde ikke kunnet bli til uten nødvendig bistand fra Marc Maure og ICOMs dokumentasjonssenter i Paris ved Elisabeth Jani.

John Aage Gjestrum er norsk forskningsrådsstipendiat $i$ museologi, knyttet til Institutionen for museologi, Umea Universitet.

Adr: N-2846 Boverbru, fax. +47-61196013

e-mail: johnag@sn.no 